\title{
The effect of post-harvest processing on the nutrient composition of BRRI Dhan 28 rice grain grown under alternate wetting and drying
}

\author{
N. Falconer ${ }^{1,2,3}$, J. Kyle ${ }^{2}$, A. Price ${ }^{1}$, G. Norton ${ }^{1}$ and W. Russell ${ }^{3}$ \\ ${ }^{1}$ School of Biological Sciences, Zoology Building, Tillydrone Avenue, Aberdeen, AB24 2TZ, \\ ${ }^{2}$ Institute of Applied Health Sciences, Polwarth Building, Foresterhill, Aberdeen, AB25 2ZD and \\ ${ }^{3}$ Rowett Institute of Nutrition and Health, Foresterhill, Aberdeen, AB25 2ZD
}

Rice (Oryza sativa L.) is one of the main staple crops worldwide feeding roughly half of the population ${ }^{(1)}$. On average, Bangladeshis consume between $450-600 \mathrm{~g}$ of rice daily; this is roughly $50 \%$ of the total daily calorie intake ${ }^{(2)}$. Rice is a water intensive crop, traditionally cultivated on flooded fields ${ }^{(3)}$. This is of concern when considering issues such as water scarcity, and the anaerobic soil conditions created by flooding can increase arsenic contamination of rice grain (4). To address these issues, alternate wetting and drying (AWD) has been implemented in some regions ( 5 ). This alternative method of cultivation is known to mitigate arsenic levels in grain, however it is not known if the nutritional content changes. Furthermore, most nutritional studies have focused on brown rice grain not representative of the nutrient content of rice as eaten to the consumer. Therefore, this study looked at the combined effect of cultivation methods and post-harvest processing on the nutritional content of rice, to determine which had the greater impact on selected contaminants, macronutrients, minerals and phytates.

BRRI Dhan 28, a rice variety commonly grown in Bangladesh, was grown under AWD and conventional cultivation practices in 2013, then subjected to three different post-harvest treatments: either parboiling, milling, or parboiling and milling, with brown rice as a control $(n=4)$. General linear modelling was run using Minitab 17.

In general, apart from a $30.5 \%$ increase in cadmium content $(\mathrm{p}=0.024)$ and a $17.1 \%$ reduction in phytic acid $(\mathrm{p}<0.001)$ in brown rice as a result of AWD cultivation, post-harvest processing had a greater impact on the nutrient profile in comparison to cultivation.

Milling had the largest effect, reducing most minerals, protein, and fat content overall $(\mathrm{p}<0.001)$; protein was reduced by 14.9 $26.7 \%$, iron was reduced by $77.7-87.8 \%$, zinc was reduced by $25.5 \%$, and fat reduced by $64.0-72.0 \%$.

Parboiling also had a notable effect on calcium and resistant starch; calcium was increased by $27.5-39.0 \%(\mathrm{p}<0.001)$ and resistant starch was increased by $53.8-71.4 \%(\mathrm{p}<0.001)$.

Changing to AWD cultivation did not have a significant impact on the nutrient quality of rice, but a possible unintended consequence is increased cadmium levels, which occurred in this study.

Post-harvest processing significantly reduced nutrient levels in most cases and may offset positive outcomes achieved by cultivation. Thus, when implementing alternative cultivation methods such as AWD, post-harvest processing must be considered due to the large effect on nutritional content and to be more representative of consumers' diets.

1. Mottaleb KA, and Mishra AK (2016) J Agri Appl Econ 48, 298-319

2. Islam S, Rahman MM, Islam, MR and Naidu R (2017) Sci Total Environ 601, 122-131

3. Norton GJ, Travis AJ, Danku JM, Salt DE, Hossain M, Islam MR \& Price AH (2017) Food Energy Secur 6, 98-112 